\title{
Repensando la identidad de la mano de los feminismos a la búsqueda de nuevas alianzas
}

Rethinking the identity by the hand of feminisms in search of new alliances

Marian Pérez Bernal

Universidad Pablo de Olavide de Sevilla mdperber@upo.es

DOI: http://doi.org/10.15366/bp2019.20.013

Bajo Palabra. II Época. No20. Pgs: 227-244 
Este trabajo ha sido realizado gracias a la financiación del Proyecto de Investigación "El desván de la razón: Cultivo de las pasiones, identidades éticas y sociedades digitales"

(FFI2017-82535-P: PAIDESOC) Entidad financiadora: Ministerio de Educación y Ciencia.

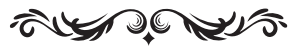

\section{Resumen}

Un tiempo de crisis de las instituciones como el que vivimos puede ser una gran oportunidad para que el feminismo ocupe un papel protagonista en el horizonte político. Para ello es preciso que seamos capaces de establecer puentes entre los diferentes feminismos. Repensar la identidad teniendo presente las múltiples lealtades que en ocasiones se entrecruzan en ella puede ayudar a establecer nuevas alianzas entre las distintas corrientes feministas. Estas alianzas darían más fuerza a las reivindicaciones feministas.

Palabras Clave: Identidad, Feminismo, Género, Feminismo postcolonial.

\section{Abstract}

At times like today's institutional crisis, feminism might have the potential to become a core asset on the political horizon. I line with this, bridges between different feminisms should be built. Rethinking identity by taking on board the intertwined multiple loyalties might help establish new alliances among the different feminist approaches. Such alliances would strengthen feminist demands even more.

Keywords: Feminism, Genre, Identity, Postcolonial Feminism 


\section{Repensando la identidad a la búsqueda de nuevas alianzas dentro del feminismo}

LA CRISIS DEL SUJETO que trajo consigo la Postmodernidad y la llegada posterior de las teorías queer y de los estudios postcoloniales supusieron un importante golpe para el feminismo reivindicativo que seguía hablando de sujetos. El feminismo quedó reducido a lo que se denominó feminismo hegemónico, un bloque monolítico «blanco, etnocéntrico, de clase media y heterosexual» del que nadie debería querer formar parte ${ }^{1}$. Desde hace años las feministas negras, latinas o lesbianas han recordado los límites de la agenda del feminismo blanco y heterosexual y lo parcial y sesgado que era el concepto de "la Mujer" que durante muchos años se empleó. La explosión del discurso identitario y el florecimiento de una identidad cada vez más monolítica y cerrada vino a agravar el panorama haciendo muy difícil que podamos encontrar un sujeto del feminismo que permita dar una imagen más fiel de la multiplicidad y diferencia que existen entre las mujeres y que permita que todas nos podamos sentir cómodas luchando dentro de él. Escuchemos a Francesca Gargallo:

Las mujeres no inician un proceso de lucha por sus derechos, reivindicando su cuerpo, su imaginario, su espacio y sus tiempos en la revisión total de la política porque son francesas o nasa, mexicanas o mapuche, sino porque un sistema que otorga privilegios a los hombres -y a lo que considera propio de ellos, lo masculino- las oprime. La acción feminista es una confrontación con la misoginia. ${ }^{2}$

Repensar esto y construir nuevos pactos nos obliga a repensar la cuestión de la identidad y la genealogía del feminismo. Decía Celia Amorós que la genealogía es una forma de legitimación que nos permite fundar en el pasado las reclamaciones del presente. La reivindicación de esa genealogía es fundamental porque es lo que nos convierte en lo que hemos llegado a ser hoy y hablando de la identidad eso no se puede obviar. Solo conociendo nuestro pasado podremos, en el futuro, reafirmar nuestra identidad. Ahora bien -y aquí comienzan los problemas- si entendemos el

\footnotetext{
${ }^{1}$ De Miguel Álvarez, Ana: "La dialéctica de la Teoría Feminista: lo que nos une, lo que nos separa, lo que nos hace avanzar", Daimon. Revista Internacional de Filosofía, no 63, 2014, p. 197.

2 Gargallo Celestini, Francesca: "Los feminismos de las mujeres indígenas: acciones autónomas y desafío epistémico", en Espinosa, Yuderkys, et. al (Eds.): Tejiendo de otro modo: Feminismo, epistemología y apuestas descoloniales en Abya Yala, Editorial Universidad del Cauca, 2014, p. 375.
} 
feminismo como la lucha de todas las mujeres que se oponen al patriarcado, tendríamos que construir una nueva genealogía considerando la historia de muchas mujeres a las que hasta ahora no se les ha prestado atención. La obra Tejiendo de otro modo: Feminismo, epistemología y apuestas descoloniales en Abya Yala, plantea como uno de sus objetivos reinterpretar el pasado a la luz de un nuevo giro que se enfrente a la mirada eurocéntrica y burguesa del feminismo clásico. Betty Lozano afirma que descolonizarse significa pensar la propia historia con categorías propias y para ello es preciso desprenderse del conocimiento europeo ${ }^{3}$. No solo es necesario que las feministas latinoamericanas construyan su historia, es también preciso que nosotras la conozcamos. La declaración de los derechos de la mujer y de la ciudadana de Olympe de Gouges es fundamental, pero estas experiencias también lo son. No se trata solo de conocer esos testimonios, sino que se trataría de construir un proceso dialógico. La heterodesignación no solo ha procedido de los varones, también nosotros hemos caído mucha veces en ella ${ }^{45}$. Cito a Ochy Curiel:

Paralelamente el reto ético y político de las feministas europeas y norteamericanas implicará reconocer estas experiencias teóricas y políticas como parte del acervo y la genealogía feminista, pues solo así será posible un feminismo transnacional basado en la complicidad y solidaridad de muchas de las feministas que compartimos los mismos proyectos políticos de emancipación. ${ }^{6}$

El feminismo siempre ha sido su mejor crítico. Señalar la importancia de la interseccionalidad a la hora de analizar la situación de opresión de las mujeres supuso un importante paso en el movimiento emancipatorio. Pero debemos ir más allá. No se trata solo de que cada mujer pueda construir su discurso, sino que se trataría de ver cómo podríamos conjugar todas esas voces individuales para que, sin perder su personalidad, se puedan construir nuevas alianzas. Se trata de construir

\footnotetext{
${ }^{3}$ Lozano Lerma, Betty R.: "El feminismo o puede ser uno porque las mujeres somos diversas. Aportes a un feminismo negro descolonial desde la experiencia de las mujeres negras del Pacífico colonial”, en Espinosa, Yuderkys, et.al. (Edits.): op. cit., p. 338.

${ }^{4}$ Muchas veces se han usado esos testimonios como materia prima sobre la que teorizar con el objetivo de la búsqueda de financiación sin preocuparse ni pretender que ellas sean sujetos de su experiencia y de su teorización sobre ella. La narración, que es fundamental, en la construcción de la identidad, no es relatada por las propias mujeres sino que son otras las que construyen su narración.

5 Muchas veces se han usado esos testimonios como materia prima sobre la que teorizar con el objetivo de la búsqueda de financiación sin preocuparse ni pretender que ellas sean sujetos de su experiencia y de su teorización sobre ella. La narración, que es fundamental, en la construcción de la identidad, no es relatada por las propias mujeres sino que son otras las que construyen su narración.

${ }^{6}$ Curiel Pichardo, Ochy: "Descolonizando el feminismo. Una perspectiva desde América Latina y el Caribe", Primer Coloquio Latinoamericano sobre Praxis y Pensamiento Feminista, Junio 2009, Buenos Aires, p.8 (URL oficial: http://feministas.org/IMG/pdf/Ochy_Curiel.pdf).
} 
pactos políticos entre feministas de contextos diferentes con experiencias teóricas y políticas muy distintas sin que ello suponga renunciar a las múltiples diferencias que nos atraviesan. No podemos renunciar a la posibilidad de construir un discurso feminista utópico, pero al mismo tiempo posible, que nos englobe a todas. La meta de esos acuerdos sería construir un proyecto político de emancipación basado en la complicidad y la solidaridad de feministas de orígenes en ocasiones opuestos. Según Ana de Miguel el capitalismo global reclama la necesidad de un feminismo sin frontera, consciente de las diferencias, pero capaz de construir estrategias comunes $^{7}$. La brasileña Rita Segato se queja de que a partir de los ochenta el vaciamiento de la política y su reducción a una pelea basada en el cerramiento de las identidades subrayó las fronteras entre las identidades fomentando la incomprensión y el segregacionismo. Según Segato esto condujo al abandono de los ataques a un objetivo mayor para el que es importante estar unidas, como, por ejemplo, la lucha contra el capitalismo ${ }^{8}$. En la misma línea la dominicana Yuderkys Espinosa frente a los terribles efectos de la globalización reivindica la posibilidad de una comunidad feminista transfronteriza, anticapitalista y descolonizada sostenida en la idea de 'diferencias comunes'?

Para establecer esos nuevos pactos es preciso replantear el proyecto feminista desde una mirada geopolíticamente situada que nos permita repensar la construcción de una subjetividad feminista. Se trata de identificar aquellos elementos que nos permiten configurar un sujeto político más allá de las enormes diferencias. Ahora bien, no valen los atajos. No vale decir que como todas somos mujeres todas precisamos lo mismo porque no es cierto. La emergencia de un nuevo sujeto del feminismo implica detenernos en esa diversidad empírica que, en ocasiones, hemos obviado en un afán equivocado de lograr un discurso de carácter universal. Como muy bien ha señalado Griselda Gutiérrez el feminismo ha redefinido la forma de hacer política planteando la posibilidad y la deseabilidad de construcciones democráticas verdaderamente pluralistas. En esa tradición en la que nos queremos insertar. Debemos ser conscientes de las identidades propias de cada corriente feminista antes de ser capaces de encontrar auténticos puentes que nos permitan ir más allá de ellos. Hay demasiado en juego para renunciar a seguir pensando nuevas formas de sororidad. No podemos renunciar a las preguntas incómodas y debemos desconfiar de los lugares que nos parecen seguros y esto implica plantearse qué puede significar

\footnotetext{
7 De Miguel Álvarez, Ana: "La dialéctica...”, op. cit. p. 200.

${ }^{8}$ Segato, Rita: La Nación y sus Otros. Raza, etnicidad y diversidad religiosa en tiempos de Políticas de la Identidad, Argentina, Prometeo Libros, 2007, pp. 16 y 19.

9 Espinosa, Yuderkys: "Etnocentrismo y colonialidad en los feminismos latinoamericanos: complicidades y consolidación de las hegemonías feministas en el espacio transnacional”, en Yuderkys, et.al. (Edits.): op. cit.p. 312.
} 
el feminismo para las diferentes comunidades. Los afectos y las confianzas también se construyen.

En su trabajo "Hacia la construcción de un feminismo descolonizado" Ochy Curiel se quejaba de lo poco que se había hecho para complejizar el sujeto colectivo del feminismo ${ }^{10}$. A una cuestión muy parecida apuntaba Rosi Braidotti al reivindicar la necesidad de consultar las experiencias de las mujeres de la vida real ${ }^{11}$. Ambas reivindican abandonar cualquier imagen abstracta acerca de qué significa ser mujer y pensar a partir de la experiencia de las mujeres de la vida real. Recordemos el discurso ‘¿Acaso no soy yo una mujer?’ de Sojourner Truth en la Convención de los Derechos de la Mujer de Akron en 1852:

Pero, ¿¿de qué están hablando todos aquí? Ese hombre de allí dice que las mujeres necesitan ayuda al subirse a los carruajes, al cruzar las zanjas y que deben tener el mejor sitio en todas partes, ¡Pero a mí nadie me ayuda con los carruajes, ni a pasar sobre los charcos, ni me dejan un sitio mejor! ¿Y acaso no soy yo una mujer? ¡Miradme! ¡Mirad mi brazo! He arado y plantado y cosechado, y ningún hombre podía superarme. ¿Y acaso no soy yo una mujer? ${ }^{12}$

En aquella Convención todos hablaban de la mujer pero Sojourner Truth no se reconocía en nada de lo que allí se decía. Su "ser negra" nadie lo ponía en duda y parece que eso no lo tenía que demostrar. Es su ser mujer lo que ella está reivindicando. Decían hablar de la mujer pero en realidad hablaban solo de las mujeres blancas y de clase alta. El discurso de Sojourner Truth -y por eso nos interesa- llevaba implícito un cuestionamiento de la homogeneidad de la identidad de género $\mathrm{y}$ es fundamental en la formación de un discurso sobre los elementos inseparables de género-etnia en el caso de mujeres afrodescendientes y en el reconocimiento de la heterogeneidad de las experiencias de mujeres. E igual que Truth se planteaba a mediados del siglo XIX qué significaba ser mujer, Curiel se replantea en el siglo XXI de qué estamos hablando cuando hablamos de feminismo:

(...) ¿ ¿cuál es el feminismo que queremos impulsar, vivir, experimentar, como propuesta transformadora y radical en países postcoloniales como los nuestros, que surja desde nuestras experiencias, que nos permita cuestionarlas y a la vez modificarlas y cambiar este mundo por otro que no sea patriarcal, ni racista, ni heterosexista, ni clasista? ${ }^{13}$

${ }^{10}$ Curiel Pichardo, Ochy: "Hacia la construcción de un feminismo descolonizado", en Espinosa, Yuderkys et.al.: op. cit. p. 333.

${ }_{11}$ Braidotti, Rosi: "El sujeto en el feminismo", en Feminismo, diferencia sexual y subjetividad nómade. Barcelona, Gedisa, 2004 (Edición original 1991), p. 19.

12 Truth, Sojourner: "Convención de los derechos de la mujer", en Jabardo, Mercedes (Eds.): Feminismos negros. Una antologia, Madrid, Traficantes de sueño, 2012, p.59.

${ }_{13}$ Curiel Pichardo, Ochy: "Hacia...", op. cit. p. 325. 
La emergencia de un nuevo sujeto del feminismo implica de forma previa el detenernos en esa diversidad empírica. Los detalles, a veces, son muy importantes, sobre todos cuando tratamos de negarlos. Para caracterizar este sujeto colectivo del feminismo es necesario tener presente la clase, la raza y la sexualidad y, al mismo tiempo, tener presente las condiciones materiales, los contextos y las experiencias situadas de las mujeres ${ }^{14}$. Se trata de construir un pensamiento propio de acuerdo con las experiencias concretas. Partimos de la idea según la cual las identidades se construyen. La feminista argelina Wassila Tamzali, al analizar su identidad y como era vista por los otros, se pronuncia así:

Como todo el mundo, acarreo una identidad con sus defectos de uso; por utilizar la expresión de Walter Benjamin, "una vasija rota que hubiera pegado", de la que habría que describir las curvas, las mezclas, los agujeros, las rugosidades, en una palabra, declinar las historias inscritas en ella. ¡Qué más da! Mis interlocutores que olvidan su propia complejidad, me acosan con preguntas perentorias - ¿musulmana?, ¿urbana?, ¿francófona?, ¿burguesa?- que hacen que unos simples adjetivos calificativos se convertían en temibles determinativos. Y cuanto más se me pide que diga quién soy, más difícil me resulta nombrarme. ${ }^{15}$

Tamzali se presenta como una mujer laica y librepensadora que forma parte de una sociedad de tradición musulmana con la que se identifica. Se presenta como humanista, anticolonialista, demócrata y feminista y no está dispuesta a renunciar a ninguna de estas identidades. Cada uno de estos rasgos contribuyó a ser quién hoy es y a pensar cómo piensa. Veamos ahora un ejemplo de la tradición latinoamericana. A mediados de los ochenta Lugones vuelve a Buenos Aires y se presenta a unas oposiciones de cátedra. Todos eran varones y aparece una mujer. Dejo que Francesca Gargallo lo cuente:

(...) se presentó también una mujer. Para colmo, joven; para colmo, casi extranjera (hacía veinte años que residía en EEUU); para colmo, feminista; para colmo anarquista; para colmo, lesbiana militante. Y para colmo de los colmos, ella, María Cristina Lugones, hacía de cada una de estas inscripciones una oportunidad de discusión ética, de connotaciones absolutamente prácticas y políticas, en lugar de proponer una escolástica sobre Aristóteles y Kant. ${ }^{16}$

Lugones era todo eso y todo eso se materializaba de una forma u otra en su pensamiento y, por supuesto, todo eso escandalizó. Estamos hablando de identidad pero no de esencias. Frente al discurso identitario esencialista consideramos que las

\footnotetext{
14 Idem.p. 333.

15 Tamzali, Wassila: Carta de una mujer indignada. Desde el Magreb a Europa, Madrid, Cátedra, 2011, p. 32.

${ }^{16}$ Gargallo Celestini, Francesca: Las ideas feministas latinoamericanas, Colombia, Ediciones desde abajo, 2004, p. 76.
} 
identidades son producto de relaciones históricas que pueden ser analizadas y deconstruidas. Confiamos en una identidad alejada de rasgos esencialistas, sustentada sobre las experiencias de la vida y sobre la práctica de mujeres. Me gusta la posición respecto a esta cuestión de F. Gargallo:

(...) el énfasis feminista en la corporización va de la mano con un repudio radical del esencialismo. En la teoría feminista, una habla como mujer, aunque el sujeto mujer no es una esencia monolítica definida de una vez para siempre, sino que es más bien el sitio de un conjunto de experiencias múltiples y complejas y potencialmente contradictorias, definido por variables que se superponen, tales como las de clase, raza, edad, estilo de vida, preferencia sexual y otras. ${ }^{17}$

A la hora de complejizar el sujeto colectivo del feminismo es necesario tener presente las condiciones materiales, los contextos y las experiencias situadas de las mujeres. La experiencia de las mujeres en la vida real es la noción central que debe sustentar toda esta investigación. Cuando se ubican culturalmente las experiencias de las mujeres se comienza a entender que el género no es una categoría universal, estable y descontextualizada. Entramos en esta cuestión a partir de lo que se ha denominado "políticas de localización" y "posiciones de ubicación".

Según Rosi Braidotti para la teoría feminista, la única manera coherente de hacer acotaciones teóricas generales consiste en tomar conciencia de que uno está realmente localizado en algún lugar específico. La propia visión intelectual no es una actividad mental desincardinada sino que se halla siempre vinculada con el lugar desde el que uno está hablando. Al tratar esta cuestión Braidotti parte de las políticas de localización de Adrienne Rich ${ }^{18}$. Como nos recordaba Gargallo las nacionalidades no explican que nos hagamos feministas pero, y esto lo añado yo, sí ayudan a entender qué tipo de feminismo vamos a defender y cómo nos posicionamos respecto a él. No es lo mismo ser feminista en España que en el Caribe:

¿Cómo actuar como feministas en los contextos latinoamericanos y caribeños atravesados por conflictos armados internos, desplazamiento forzado, pobreza extrema, racismo, violencia contra las mujeres y un "socialismo de siglo XXI" con tintes dictatoriales ${ }^{19}$ ?

Citando los trabajos de Oyewùmi y de Allen, Lugones subraya como el estatus de las mujeres blancas no se extendió a las mujeres colonizadas. Si bien sí reciben

\footnotetext{
${ }_{17}$ Ibid. pp. 87-88.

${ }_{18}$ Braidotti, Rosi: op. cit. pp. 15-16.

19 Curiel Pichardo, Ochy: "Descolonizando..., op. cit. p. 4.
} 
el estatus inferior propio del género mujer, no recibieron ninguno de los privilegios propios de las mujeres blancas ${ }^{20}$. Reciben lo malo pero no lo bueno. Recordemos aquí las quejas de Sojourner Truth en el siglo XIX tan similares a las que estamos viendo ahora. Ella era una mujer pero a ella nadie le cedía el mejor asiento en el carruaje ni le ayudaba a cruzar las calles. Es preciso pues repensar el proyecto feminista desde una mirada geopolíticamente situada. Y situándonos en las distintas ubicaciones o posiciones debemos preguntarnos ¿̨cuál es la posición feminista aquí?

Las políticas de localización serían equivalente a lo que Chandra Mohanty denomina "posiciones de ubicación". Según Mohanty el feminismo "occidental" desde una posición etnocéntrica homogeneiza a las mujeres del Tercer Mundo como si tuvieran todas las mismas características. Mohanty reivindica la necesidad de analizar las diferentes posiciones de ubicación para no crear una falsa imagen de qué son las mujeres del Tercer Mundo ${ }^{21}$.

La falta de sensibilidad cultural frente a sus problemas específicos y concepciones del mundo ha dificultado muchas veces el diálogo. Hernández Castillo señala, por ejemplo, cómo la falta de reconocimiento de las diferencias culturales ha dificultado la construcción de un movimiento feminista nacional que incluya a indígenas y mestizas en México. Cita el caso de la Segunda Ley Revolucionaria de Mujeres propuesta por las indígenas zapatistas incluyen un artículo que prohíbe la infidelidad. Esta modificación a la Primera Ley Revolucionaria de Mujeres fue considerada por las feministas urbanas como una medida conservadora, producto de la influencia de la iglesia en las comunidades indígenas ${ }^{22}$. Hernández del Castillo señala hasta qué punto, al hacer esa valoración, no se estaban teniendo en cuenta las experiencias diferentes de estas mujeres La demanda de las mujeres indígenas debe verse en el marco de una realidad en la que la infidelidad masculina y bigamia son justificadas culturalmente en nombre de la tradición y se encuentran estrechamente vinculadas con las prácticas de violencia doméstica. Las mujeres indígenas no reclaman la modificación por una cuestión moral sino que pretenden con ella es luchar contra la posición de vulnerabilidad en la que se encuentran dentro de la comunidad ${ }^{23}$.

${ }^{20}$ Lugones, María: “Colonialidad y género”, en Espinosa Miñoso, Yuderkys et. al. (Eds): op. cit. p. 69.

${ }^{21}$ La 'violencia epistémica' es tal que la 'mujer del tercer mundo' queda atrapada doblemente por la colonización discursiva del feminismo de occidente que construye a la 'Otra' Monolítica de América Latina, y por la práctica discursiva de las feministas del Sur, quienes, estableciendo una distancia con ella y, al mismo tiempo, manteniendo una continuidad con la matriz de privilegio colonial, la constituye en la otra de la Otra." (Espinosa, Yuderkys: op. cit. p. 318).

${ }^{22}$ Hernández Castillo, Rosalva A.: "Entre el etnocentrismo feminista y el esencialismo étnico. Las mujeres indígenas y sus demandas de género", en Espinosa, Yuderkys et. al.: op. cit. p. 288.

${ }^{23}$ Ibid. p.290. Braidotti remarca que si bien hablar de lo lejano es fácil se omiten en cambio con mayor frecuencia las cuestiones más cercanas a las realidades locales. Pienso que existe una marcada tendencia a postergar la confrontación con el "Otro" más inmediato (Braidotti, Rosi: op. cit. pp. 76-77). 


\section{Las situaciones fronterizas y las múltiples lealtades}

En el arTículo "Crítica poscolonial desde las prácticas políticas del feminismo antirracista", Curiel alaba cómo el feminismo negro fue capaz de detectar el sesgo racista del feminismo, y, al mismo tiempo, denunciar el sesgo sexista del movimiento por los derechos civiles haciendo así explícito como el racismo, junto con el sexismo y el clasismo, afecta a las mujeres ${ }^{24}$. Nos interesa resaltar aquí cómo tenemos que enfrentarnos de forma continuada a la intersección de discursos. Retomo aquí uno de los requisitos mínimos que según la profesora Guerra debemos tener presente a la hora de pensar nuestra identidad:

No puede desestimar la referencia al contexto, a la intersección de discursos y a la pertenencia a múltiples comunidades que nos vertebra. Toda instalación abstracta se revela falaz. Lo concreto exige sus títulos en respuesta a la necesidad de respetar la pluralidad y las diferencias. ${ }^{25}$

En este repensar geopolíticamente situado hay situaciones que facilitan el que seamos capaces de ver las aristas problemáticas. Me refiero a las situaciones fronterizas. Una situación fronteriza extraña, una identidad híbrida latinoamericana y española, que podía resultar incómoda, llevó a Liliana Suárez, por ejemplo, a replantearse las raíces eurocéntricas del feminismo ${ }^{26}$. La obligó a repensar el discurso y no conformarse con lo establecido. El feminismo chicano defiende una identidad híbrida y mestiza. Desde su situación fronteriza cuestiona tanto el nacionalismo chicano como el racismo norteamericano, a la vez que el racismo y el etnocentrismo del feminismo anglosajón, y el heterosexismo de ambos, tomando como marco el contexto global del capitalismo ${ }^{27}$.

Según Hernández Castillo esta doble lucha resulta bastante habitual entre las mujeres indígenas. Frente al Estado reivindican el derecho a la diferencia cultural y en el interior de sus comunidades, luchan por cambiar las tradiciones que consideran contrarias a sus derechos. Pone como ejemplo de esto la lucha de la comandante Esther y de la médica María de Jesús Patricio del EZLN que reclamaban el derecho a una cultura propia, al mismo tiempo que exigían a esa cultura tradicional que acabe con aquellos elementos que resultan opresivos y excluyentes para las mujeres.

${ }^{24}$ Curiel Pichardo, Ochy: "Crítica poscolonial desde las prácticas políticas del feminismo antirracista", Nómadas, no26, Abril, 2007, p. 95.

${ }^{25}$ Guerra Palmero, María José: “¿ «Subvertir» o «situar» la identidad? Sopesando las estrategias feministas de Judith Butler y Seyla Benhabib”, Daimon, Revista de Filosofia. 1997, n 14, pp. 154.

26 Suárez Navaz, Liliana \& Hernández, R. A. (2008) "Colonialismo, gobernabilidad y feminismos poscoloniales", en Suárez Navaz, L. \& Hernández, R. A. (Eds.): Descolonizando el feminismo. Teoría y prácticas desde los márgenes, Madrid, Cátedra, pp. 32-33.

${ }_{27}$ Curiel Pichardo, Ochy: “Crítica...”, op. cit. pp. 96-97. 
Su lucha es una lucha no por el reconocimiento de una cultura esencial, sino por el derecho de reconstruir, confrontar o reproducir esas culturas, no en los términos establecidos por el estado, sino en los delimitados por los propios pueblos indígenas en el marco de sus propios pluralismos internos ${ }^{28}$. No podemos perder de vista que una condición básica de la conciencia de la identidad humana es que uno solo puede conocerse en relación con los otros. El sujeto está definido por muchas variables diferentes. La clase, la raza, el sexo, la edad, la nacionalidad y la cultura se yuxtaponen para definir y codificar los niveles de nuestra experiencia. Según De Lauretis en los textos feministas nos encontramos con una identidad múltiple y mudable, una identidad compuesta por representaciones heterogéneas y heterónomas de género, raza y clase y compuesta a través de lenguajes y culturas ${ }^{29}$. Entramos así en una cuestión que nos parece central, como es el problema de la identidad mudable que se ve reflejada en la cuestión de las dobles (triples o cuádruples) lealtades y la constante necesidad de posicionarnos en una de esas identidades y, al mismo tiempo, la capacidad de verlas críticamente. Escuchemos a Segato:

Las mujeres -tanto indígenas como afroamericanas- que han actuado y reflexionado divididas entre, por un lado, la lealtad a sus comunidades y pueblos en el frente externo y, por el otro, a su lucha interna contra la opresión que sufren dentro de esas mismas comunidades y pueblos, han denunciado frecuentemente el chantaje de las autoridades indígenas que las presionan para que posterguen sus demandas como mujeres a riesgo de que, de no hacerlo, acaben fragmentando la cohesión de sus comunidades tornándolas más vulnerables para la lucha por recursos y derechos. ${ }^{30}$

Algo parecido encontremos en el caso de Gloria Anzaldúa:

Soy una puente columpiada por el viento, un crucero habitado por torbellinos, (...) montada a horcajadas en el abismo. "Tu lealtad es a la Raza, el Movimiento Chicano", me dicen los de mi raza. "Tu lealtad es al Tercer Mundo", me dicen mis amigos negros y asiáticos. "Tu lealtad es a tu género, a las mujeres", me dicen las feministas. También existe mi lealtad al movimiento gay, a la revolución socialista, a la Época Nueva, a la magia y lo oculto. Y existe mi afinidad a la literatura, al mundo artístico. ¿Quién soy? Una lesbiana feminista tercermundista inclinada al marxismo y al misticismo. Me fragmentarán y a cada pequeño pedazo le pondrán una etiqueta. ${ }^{31}$

\footnotetext{
${ }^{28}$ Hernández Castillo, R.: op. cit. pp. 286-288

29 De Lauretis, Teresa: Feminist Studies/Critical Studies, Bloomington, Indiana University Press, 1986, p. 9.

30 Segato, Rita: "Colonialidad y patriarcado moderno: expansión del frente estatal, modernización y la vida de las mujeres”, en Espinosa, Yuderkys et. al.: op. cit. p. 77.

31 Anzaldúa, Gloria: "La prieta”, en Moraga, C. \& Castillo, A. (Eds.): Esta puente, mi espalda. Voces de mujeres tercermundistas en los Estados Unidos, San Francisco, ISM Press, 1988, p. 165.
} 
Desde su posición de lesbiana y feminista, Anzaldúa no solo fue crítica con el imperialismo norteamericano, sino que también denunció los usos y costumbres de su cultura originaria que la subordinaban, entre otras cosas, por su condición de lesbiana. Anzaldúa rechaza las visiones parciales de sus amigos, incapaces de verla como un todo y eligiendo de su relato completo solo los hilos que a cada uno le interesaba. Como representante del feminismo chicano ha sido pionera de lo que hoy se denomina pensamiento fronterizo, que expresa las limitaciones de identidades esencialistas y auténticas ${ }^{32}$. Parece que es muy complicado poder decir "soy esto y soy aquello", siempre hay que elegir. Escuchemos a Rita Segato:

Hoy en día, el reclamo de derechos y recursos se da, en los Estados Unidos, a través de la pertenencia a una minoría, como negro, como mujer, como gay, como hispánico, como asiático. Todo ciudadano es obligado a reconocerse como una de estas parcialidades y tanto la política de dominación como la política de contestación pasan por un discurso de segregación. Esto tiene sus ventajas en el proceso de reclamación de derechos, pero también un costo muy alto. Uno de los precios raramente contabilizados es que los pueblos minoritarios deben renunciar a sus aspiraciones de universalidad que, en el fondo, en el subtexto, es reservada a los valores y producciones del blanco, del euroamericano. El otro precio que se debe estar dispuesto a pagar es que se vuelve imposible pensar fuera del paradigma racial. Quien no habla desde un lugar predeterminado en ese esquema, quien no habla en términos étnicos, no tiene voz. No existe el lugar para la ambigüedad; cualquier situación de ambigüedad desestabiliza o desestructura. Nadie puede decir soy esto y soy aquello. ${ }^{33}$

Con qué nos identifiquemos dependerá de los contextos en los que nos movamos y de qué nos puede resultar que se está problematizando o criticando en un momento determinado. Por ejemplo, para la mujer lesbiana el planteo de la sexualidad liberada de los patrones reproductivos será un problema central que no podría ser eludido apelando al carácter burgués de dichas disquisiciones. Braidotti, por ejemplo, analiza la peculiar visión del nacionalismo y del patriarcado de dos filósofas yugoslavas Dasha Duhacek y Zarana Papic que analizaron cómo en la ex-Yugoslavia, el nacionalismo mató la diferencia sexual: "No es posible ser una mujer en la ex-Yugoslavia: una debe ser una serbia, una croata o una bosnia" ${ }^{34}$. Era tan fuerte en ese contexto lo que significa ser serbia o bosnia que lo demás rasgos se difuminan hasta borrarse.

\footnotetext{
32 Curiel Pichardo, Ochy: "Crítica..., op. cit. p. 97.

33 Segato, R.: La Nación..., op. cit. p.51. Cuando esto se da se habla de bi-étnico o bi-racial. Lo mismo parece suceder con el reciente reconocimiento y aceptación de la bisexualidad como una nueva categoría o nicho de orientación sexual y no como una experiencia que permitiría el reconocimiento de la fluidez de la sexualidad humana (Ibid. pp. 51-52).

34 Braidotti, R.: op. cit. p. 78.
} 
Me gustaría antes de acabar abrir un pequeño paréntesis frente a aquellos que consideran a la teoría queer como el sueńo capaz de poner fin a las identidades esencialistas y la herramienta capaz de darnos esa libertad máxima que parecería ser vivir sin etiquetas. No para todos es fácil ser queer:

En América Latina la poca gente queer que conozco se posiciona desde un lugar totalmente individualista; 'soy yo, mi identidad, no quiero etiquetas', dicen, hoy quiero ser mujer y mańana si me pongo una corbata soy hombre y voy moldeando mis identidades. Esto es bastante blanco. ¿Cuántos queer negros hemos conocido? (...) Una persona negra no puede jugar con su identidad así como así porque está atravesada por su color, por la interpretación social que se hace de su color, color político. Es la gente con más oportunidades quienes son queer. En resumen, es muy teórico, muy individualista y muy chévere en algunos sentidos pero a eso hay que meterle clase y raza. ${ }^{35}$

\section{Las identidades en continua construcción. La identidad como patchwork}

Presenté en 2016 en las VI Jornadas del Centro Interdisciplinario de Investigaciones en Género en la Universidad de La Plata (Argentina) una ponencia titulada "A la búsqueda de los hilos violetas en el entramado de la identidad" donde comparaba la identidad con un tartán. El tartán es una tela de lana con cuadros o listas cruzadas de diferentes colores característica de Escocia. En el diseño de esta tela se alternan bandas de hilos de diferentes colores entramados entre sí en ángulos rectos. A mediados del XIX se empezaron a asociar los tartanes con los clanes. Así, en el tartán Erskine nos encontramos con cuadros rojos y verdes. Si al tartán Erskine le quitamos los hilos verdes dejaría de ser lo que es. Entendía que con la identidad pasaba algo parecido. La identidad sería un entramado conformado por muchos hilos y si quitamos uno la identidad cambiaría. ¿Por qué Anzaldúa ha de elegir? ¿Por qué no van a poder convivir esos múltiples rasgos como conviven los hilos en el tartán? Escuchemos a Anzaldúa:

Lo que quiero es contar con las tres culturas, la blanca, la mexicana, la india. Quiero la libertad de poder tallar y cincelar mi propio rostro, cortar la hemorragia con cenizas, modelar mis propios dioses desde mis entrañas. Y si ir a casa me es denegado entonces tendré que levantarme y reclamar mi espacio, creando una nueva cultura "una cultura mestiza" con mi propia madera, mis propios ladrillos y argamasa y mi propia arquitectura feminista. ${ }^{36}$

\footnotetext{
35 Curiel Pichardo, Ochy: "Yo ya no creo en una solidaridad feminista transnacional así por asî", entrevista publicada en Pikara Magazine, 8.10.2014 (http://www.pikaramagazine.com/2014/10/yo-ya-no-creo-en-una-solidaridad-feminista-transnacional-asi-por-asi/)

36 Anzaldúa, Gloria. «Movimientos de rebeldía y culturas que traicionan», en bell hooks et.al.: Otras inapropiables, Madrid, Traficantes de sueńos, 2004, p. 79.
} 
En el texto de Anzaldúa vemos un distanciamiento respecto a las culturas que conforman su ser. El feminismo en cuanto pensamiento crítico es un modo autorreflexivo de análisis ${ }^{37}$. En esta misma línea se sitúa Benhabib al subrayar la importancia que tiene la posibilidad de la autorreflexión, esto es, el tomar "un distanciamiento necesario de una misma y de las propias certidumbres cotidianas". Se trataría de una suerte de exilio del propio interior para, una vez vistos desde fuera con una perspectiva crítica, reforzar los componentes de la propia identidad o desestimarlos. Cito a María José Guerra:

Benhabib nos ofrece otra manera de pensar la identidad distanciada de la tradición: finitud, fragilidad y corporeidad frente a las unidades abstractas de la apercepción trascendental. ${ }^{38}$

El feminismo es el reconocimiento de una subjetividad en proceso, fluida, que implica la construcción de formas de socialización y nuevos pactos culturales entre las mujeres partiendo de la propia corporalidad. Siguiendo a Braidotti podemos decir que reconcebir las raíces corpóreas de la subjetividad es un punto de partida para iniciar un proyecto epistemológico del nomadismo:

Las mujeres que asumen la posición de sujeto feminista como parte de la reconstrucción de lo que denomino la subjetividad femenina son, en sí mismas, una multiplicidad: escindida, fracturada y constituida a través de niveles de experiencia que se intersecan. ${ }^{39}$

Hemos tratado en nuestra ponencia de reflexionar acerca de esta identidad múltiple y compleja y las formas más adecuadas para conseguir que todos esos rasgos que conforman nuestra identidad puedan convivir sin que eso suponga un conflicto para decirme feminista. Esto es, que mi ser feminista no debe implicar una renuncia a mi etnia, a mi sexualidad, a mi religión, a mis deseos sexuales o a mi opción política. La identidad es una construcción histórica que se está formando y reformulando continuamente. Pensaba al escribir esto que había un problema en la metáfora del tartán. Los hilos deben estar todos allí cuando se comienza a realizar. Para que fuera así un auténtico tartán que recogiera todo lo que somos solo nos podría servir como sudario. La alegre metáfora se torna un poco macabra. Pensando sobre esto creo que sería más adecuado hablar de nuestra identidad como un patchwork. El genotipo, el microbioma, la raza, la etnia, la religión, la opción sexual, la clase, las experiencias,

\footnotetext{
37 Braidotti, R.: op. cit. 39.

38 Guerra Palmero, María José: op. cit. p. 151.

39 Braidotti, R.: op. cit. 83 .
} 
las circunstancias, las posiciones de ubicación podríamos decir para resumir un poco configuran las telas con las que nos las tenemos que ver. Las telas que serán más bonitas o más feas, más grandes o más pequeñas, más rotas o más nuevas y que tendremos que ir uniendo con mejor o peor fortuna.

Las identidades son fijas y flexibles al mismo tiempo, cambiables e incambiables a la vez. Al patchwork podemos ir dándole nuevas formas, podemos coser nuevos trozos que tapen aquellos que ya no nos gusta, igual que vamos cambiando el relato de nuestra vida conforme las vivencias van creciendo y conforme va cambiando lo que esperamos o lo que queremos del futuro. Curiel no puede dejar de ser negra pero su feminismo ha cambiado mucho. Me gusta escucharla en una conferencia que tuvo lugar en Granada donde recordaba, con mucho sentido del humor cómo era y cómo es, qué pensaba y qué piensa hoy. A la hora de decidir qué y cómo narramos nuestra vida el pasado se articula con los proyectos, influyen en la narración tanto lo ya vivido como lo que esperamos vivir.

Entendemos que una identidad en la que no se nos obligue a renunciar a partes de lo que somos posibilitaría el diálogo y facilitaría que se construyeran pactos entre feministas provenientes de "posiciones de ubicación" muy diferentes. Tamzali se presenta como "humanista, anticolonialista, demócrata y feminista" y dialoga desde esas identidades ${ }^{40}$. En esas identidades nos podemos reconocer muchas aunque nuestras posiciones de ubicación sean muy diferentes. Tenemos que entender que la cuestión de la identidad implica un trabajo político pero que aun así habrá rasgos que no podremos cambiar. La meta de esos acuerdos sería construir un proyecto político de emancipación basado en la complicidad y la solidaridad de feministas de orígenes opuestos. El feminismo, como la izquierda, debe ser internacionalista. Hay demasiado en juego para renunciar a seguir pensando nuevas formas de sororidad. Mohanty nos recuerda que el feminismo postcolonial no está en contra de las generalizaciones, que pueden ser útiles siempre que sean cuidadosas y respondan a estas realidades complejas ${ }^{41}$. Me gustaría terminar citando a Rosalva Hernández del Castillo:

Si el reconocimiento de las similitudes entre las mujeres nos permite crear alianzas políticas, el reconocimiento de las diferencias es requisito indispensable para la construcción de un diálogo respetuoso y para la búsqueda de estrategias de lucha más acordes a las distintas realidades culturales. ${ }^{42}$

\footnotetext{
40 Tamzaly, W.: op. cit. p. 41.

${ }^{41}$ Mohanty, Chandra T. (2008): "Bajo los ojos de Occidente: academia feminista y discursos coloniales", en Suárez Navaz, Liliana \& Hernández, R. A. (Eds.): Descolonizando el feminismo. Teoría y prácticas desde los márgenes, Madrid, Cátedra, 2008 (Edición original 1988), p. 146.

${ }^{42}$ Hernández Castillo, R.: op. cit. p. 290.
} 


\section{ReferenCias Bibliográficas}

Anzaldúa, Gloria. "La prieta», en Moraga, C. y Castillo, A. (Eds.): Esta puente, mi espalda. Voces de mujeres tercermundistas en los Estados Unidos, San Francisco, ISM press, 1988.

— «Movimientos de rebeldía y culturas que traicionan», en bell hooks et.al.: Otras inapropiables, Madrid, Traficantes de sueños, 2004.

Braidotti, Rosi. «El sujeto en el feminismo», en Braidotti, Rosi: Feminismo, diferencia sexual y subjetividad nómade. Barcelona, Gedisa, 2004 (Edición original 1991).

Curiel Pichardo, Ochy. "Crítica poscolonial desde las prácticas políticas del feminismo antirracista», Nómadas, n²6, Abril, 2007, pp. 92-101.

- «Descolonizando el feminismo. Una perspectiva desde América Latina y el Caribe», Primer Coloquio Latinoamericano sobre Praxis y Pensamiento Feminista, Junio 2009, Buenos Aires. (URL oficial: http://feministas.org/IMG/ pdf/Ochy_Curiel.pdf)

- «Hacia la construcción de un feminismo descolonizado», en Espinosa Miñoso, Yuderkys, Gómez Correal, Diana y Ochoa Muñoz, Karina (Eds.): Tejiendo de otro modo: Feminismo, epistemología y apuestas descoloniales en Abya Yala, Editorial Universidad del Cauca, 2014, pp. 325-334.

- «Yo ya no creo en una solidaridad feminista transnacional así por así», entrevista realizada por Itziar Pequeño en Pikara Magazine, 8.10.2014 (http:// www.pikaramagazine.com/2014/10/yo-ya-no-creo-en-una-solidaridad-feminista-transnacional-asi-por-asi/)

De Lauretis, Teresa. Feminist Studies/Critical Studies, Bloomington, Indiana University Press, 1986.

De Miguel Álvarez, Ana. «La dialéctica de la Teoría Feminista: lo que nos une, lo que nos separa, lo que nos hace avanzar», Daimon. Revista Internacional de Filosofia, no 63, 2014, pp.191-204. DOI: 10.6018/daimon/199711

- Neoliberalismo sexual. El mito de la libre elección, Madrid, Cátedra, 2015.

Espinosa Miñoso, Yuderkys. «Etnocentrismo y colonialidad en los feminismos latinoamericanos: complicidades y consolidación de las hegemonías feministas en el espacio transnacional», en Espinosa, Yuderkys, et. al. (Eds.): op. cit. 2009, pp. 309-334. 
Gargallo Celestini, Francesca. «Los feminismos de las mujeres indígenas: acciones autónomas y desafío epistémico», en Espinosa Miñoso, Yuderkys, Gómez Correal, Diana; Ochoa Muñoz, Karina (Eds.). op. cit. 2014, pp. 371-382.

- "Feminismo Latinoamericano», en Revista Venezolana de Estudios de la Mujer, Caracas, vol.12, no.28, 2007, pp. 17-34.

- Las ideas feministas latinoamericanas, Colombia, Ediciones desde abajo, 2004.

Guerra Palmero, María José. «¿Subvertir o situar la identidad? Sopesando las estrategias feministas de Judith Butler y Seyla Benhabib», Daimon, Revista de Filosofía no 14, 1997, pp. 143-154. DOI: 10.6018/daimon/8541

Gutiérrez Castañeda, Griselda. Perspectiva de género. Cruce de camino y nuevas claves interpretativas. Ensayos sobre feminismo, politica y filosofía, México, Editorial Miguel Ángel Porrúa, 2002.

Hernández Castillo, Rosalva Aída. «Entre el etnocenrismo feminista y el esencialismo étnico. Las mujeres indígenas y sus demandas de género», en EsPInosa Miñoso, Yuderkys; Gómez Correal, Diana; Ochoa Muñoz, Karina (Eds.): Op.cit. pp. 279-293

Lozano Lerma; Betty Ruth. «El feminismo o puede ser uno porque las mujeres somos diversas. Aportes a un feminismo negro descolonial desde la experiencia de las mujeres negras del Pacífico colonial», en Espinosa Miñoso, YuDerkys; Gómez Correal, Diana; Ochoa Muñoz, Karina (Eds.): op. cit., pp. 335-352 (Publicación original en la revista La manzana de la discordia en 2010).

Lugones, María; "Colonialidad y género», en Espinosa Miñoso, Yuderkys; Gómez Correal, Diana; Ochoa Muñoz, Karina (Eds.): Tejiendo de otro modo: Feminismo, epistemología y apuestas descoloniales en Abya Yala, Editorial Universidad del Cauca, 2014, pp. 57-73.

Mendoza, Breny. "Los feminismos y la otra transición a la democracia en América Latina”, en García de León, María Antonia: Rebeldes ilustradas. La Otra Transición, Barcelona, Anthropos, 2008.

Mohanty, Chandra T. «Bajo los ojos de Occidente: academia feminista y discursos coloniales», en Suárez Navaz, Liliana \& Hernández, R. A. (Eds.). Descolonizando el feminismo. Teoría y prácticas desde los márgenes, Madrid, Cátedra, 2008 (Edición original 1998), pp. 117-163. 
Pérez Bernal, Marian. «A la búsqueda de los hilos violetas en el entramado de la identidad", Universidad de La Plata, FAHCE-UNLP, 2016, http://jornadascinig.fahce.unlp.edu.ar/iv-2016

Segato, Rita. La Nación y sus Otros. Raza, etnicidad y diversidad religiosa en tiempos de Politicas de la Identidad, Argentina, Prometeo Libros, 2007,

— "Colonialidad y patriarcado moderno: expansión del frente estatal, modernización y la vida de las mujeres», en Espinosa Miñoso, Yuderkys, Gómez Correal, Diana; Ochoa Muñoz, Karina (Eds.). Op.cit., pp. 75-90.

Suárez Navaz, Liliana \& Hernández, R. A. (2008) «Colonialismo, gobernabilidad y feminismos poscoloniales», en SuÁrez Navaz, Liliana y Hernández, R. A. (Eds.): Descolonizando el feminismo. Teoría y prácticas desde los márgenes, Madrid, Cátedra, pp. 31-73.

Tamzali, Wassila. Carta de una mujer indignada. Desde el Magreb a Europa, Madrid, Cátedra, 2011.

Truth, Sojourner. «Convención de los derechos de la mujer», en Jabardo, Mercedes (Eds.). Feminismos negros. Una antología, Madrid, Traficantes de sueño, 2012

DOI: http://doi.org/10.15366/bp2019.20.013

Bajo Palabra. II Época. No20. Pgs: 227-244 